Claves. Revista de Historia, Vol. 3, No 5

Montevideo, julio - diciembre 2017

(pp. 101 - 127) ISSN 2393-6584

\title{
Las revoluciones rusa y mexicana en la visión conspirativa de grupos secreto-reservados mexicanos: Tecos y El Yunque (1934-1964)
}

\author{
Russian and Mexican revolutions in the conspiracy view of \\ Mexican Secret-Reserved Groups: Tecos and El Yunque \\ (1934-1964)
}

Mario Virgilio Santiago Jiménez Universidad Nacional Autónoma de México

Recibido: 01/08/2017

Aceptado: 12/10/2017

Resumen: El artículo trata el vínculo entre las revoluciones mexicana y rusa en el código conspirativo de dos grupos secreto-reservados mexicanos: Tecos y El Yunque. Se argumenta que dicha visión fue producto de la articulación del pensamiento antimoderno católico del siglo XIX, la idea de la "persecución revolucionaria”, diversos acontecimientos de la política mexicana de los años veinte y treinta asociados con el comunismo, así como de la llegada a México del ideario sobre una conspiración judía milenaria. En esta construcción fueron fundamentales la literatura formativa y los clérigos que asesoraban a los grupos, permitiendo que la base conspirativa se mantuviera a pesar del paso del tiempo.

Palabras claves: Catolicismo intransigente, revolución mexicana, revolución rusa, anticomunismo católico.

\footnotetext{
Abstract: The article discusses the link between the Mexican and Russian revolutions in the conspiracy code of two secret-reserved Mexican groups: Tecos and El Yunque. It is argued that this vision was a product of the articulation of nineteenth-century Catholic anti-modern thinking, the idea of "revolutionary persecution", various events of Mexican politics of the twenties and thirties associated with communism, as well as the arrival in Mexico of the ideology
} 
about an ancient Jewish conspiracy. In this construction the formative literature and the clerics that advised the groups were fundamental, allowing the conspiratorial base to be maintained despite the passage of time.

Keywords: Intransigent Catholicism, Mexican Revolution, Russian Revolution, Catholic Anti-Communism

\section{Introducción}

En un artículo publicado en 2005, la investigadora Beatriz Urías presentó una sugerente hipótesis: el componente del bolchevismo soviético, proyectado a través de los discursos político y pictórico, fue un eficaz instrumento para el control de las masas por parte de los regímenes mexicanos entre 1920 y 1940, sin que esto significara que la élite política tuviera claridad sobre lo que realmente significaba el socialismo. A eso se sumaron las visiones de visitantes extranjeros -especialmente estadounidenses- y las prácticas de gobiernos radicales de algunas regiones mexicanas para producir un "juego de espejos que ampliaron la ficción de un México bolchevique”. ${ }^{1}$

El tema central de este trabajo forma parte de ese "juego de espejos". En efecto, una vez que fueron confinados al bando de la "reacción" entre 1913 y 1914, los católicos políticamente activos comenzaron a definir al enemigo revolucionario y, hacia los años veinte, a identificarlo con la amenaza comunista. Sobre esta línea, argumentamos que la radicalización de algunos católicos, con el respaldo de clérigos y obispos, permitió el cruce de las "pruebas" que ofrecían los regímenes de los años veinte y treinta, el pensamiento antimoderno católico y la idea de la "persecución revolucionaria", en torno a un eje conspirativo, para concluir que existía un vínculo entre los procesos mexicano y ruso. Además, estos católicos tendrían la particularidad de militar en organizaciones secretas, mientras que su idea de conspiración incluiría a los judíos como un elemento central y novedoso. Para que esta idea se consolidara dentro del imaginario y el código ideológico de los militantes católicos, fueron necesarios el respaldo y la vigilancia constante de miembros de

1 URÍAS Horcasitas, Beatriz, "Retórica, ficción y espejismo: tres imágenes de un México bolchevique (1920-1940)", Relaciones. Estudios de historia y sociedad, El Colegio de Michoacán, vol. 26, no. 101, 2005, p. 264. 
la Iglesia, quienes fungieron como formadores y vehículos del código, así como materiales impresos que ofrecieran herramientas conceptuales y visiones históricas. Dos ejemplos particulares de lo anterior fueron los Tecos y El Yunque, fundados en 1934 y 1953 respectivamente, quienes compartieron rasgos organizativos e ideológicos cuando menos hasta 1964, justo antes de su separación formal, aunque como se verá, mantuvieron un sustrato conspirativo en sus interpretaciones históricas.

Para dar cuenta de lo anterior se han analizado distintos tipos de fuentes, destacándose dos publicaciones de las universidades que cobijaron a los grupos secreto-reservados en cuestión y que permiten evidenciar la permanencia del código conspirativo que asocia la revolución mexicana con la rusa; documentación de archivos eclesiásticos que ejemplifica la visión eclesiástica respecto a la referida vinculación, un testimonio oral recabado por el autor que permite confirmar la vinculación entre sacerdotes, literatura y seglares en torno a la visión conspirativa, así como bibliografía -generalmente menospreciadaque era utilizada para formación en los grupos secretos-reservados y que cimentó la idea de una conspiración judeo-masónico-comunista.

Con todo esto se busca, por una parte, abonar a la idea de un universo católico complejo, heterogéneo y convulso en el México de la primera mitad del siglo XX más allá de lecturas lineales y reduccionistas; por otro lado, se reivindica lo "irracional", en este caso la lectura que vincula las revoluciones mexicana y soviética a partir de un código conspirativo, como un objeto de estudio válido y necesario para comprender el quehacer y pensar de algunas derechas radicales.

El trabajo se divide en cuatro apartados: en el primero se muestran y analizan dos fragmentos de trabajos presentados en 1991 y el año 2000 en los que se sintetiza la asociación entre las revoluciones mexicana y bolchevique, como muestra de la supervivencia de la interpretación conspirativa; en el segundo apartado se describe de forma general el pensamiento integral intransigente y la idea de la "persecución revolucionaria", además se señalan algunos acontecimientos y documentos que funcionaron como "pruebas" y refuerzos de la asociación conspirativa en el ideario de los católicos militantes 
de grupos secretos-reservados; el tercer apartado se centra en la tradición de estos grupos así como en los clérigos y textos que funcionaron como puentes y cimientos de la visión conspirativa; la cuarta parte corresponde a las consideraciones finales.

\section{Retrospectiva del enemigo}

En el año de 1991, la Universidad Popular Autónoma del Estado de Puebla (UPAEP) publicó una historia de la institución o, mejor dicho, un ensayo histórico sobre el grupo de personas que fundó la universidad. De hecho, los autores -Juan Louvier Calderón, Manuel Antonio Díaz Cid y José Antonio Arrubarrena- formaban parte del mismo y eran profesores de la UPAEP.

Luego de un capítulo en el que se reivindica el "origen cristiano" de las universidades, el trabajo ofrece un contexto sucinto sobre instituciones educativas de nivel superior en la Nueva España y México, destacando la polémica educativa durante el periodo revolucionario y en especial en torno a la Constitución de 1917:

[...] en el Congreso Constituyente se impuso un grupo de diputados radicales marxistas y anarquistas, hostiles al proyecto de Constitución presentado por Carranza, principalmente en lo referente al texto del Artículo Tercero sobre la educación. Este grupo [...] logró que se aprobara el texto del artículo $3^{\circ}$ que destruye la libertad de educación, entregándola al monopolio del Estado. ${ }^{2}$

Considerando el argumento del capítulo uno, el posicionamiento del párrafo citado es claro en cuanto al rechazo católico de la presencia estatal en la educación, pero destaca la idea de que los causantes de elevar este tema a rango constitucional hayan sido "radicales marxistas y anarquistas", una afirmación anacrónica si consideramos que algunos de los sujetos a los que se hace referencia -como Francisco J. Múgica y Luis G. Monzón- no expresaban posiciones definidas dentro de un corpus ideológico estricto. Eran "radicales" pero no marxistas ni anarquistas.

${ }^{2}$ LOUVIER Calderón, Juan; DÍAZ Cid, Manuel; ARRUBARRENA Aragón, José Antonio, Autonomía universitaria. Luchas de 1956 a 1991. Génesis de la UPAEP, México, Instituto de Investigaciones Humanísticas - Universidad Popular Autónoma del Estado de Puebla, 1991, p. 19. 
Sin embargo, la idea es fundamental para el argumento de los autores que unos párrafos adelante afirman:

\begin{abstract}
“En 1934 el gobierno del general Lázaro Cárdenas modificó el Artículo Tercero para que el monopolio educativo del Estado impartiera exclusivamente "educación socialista-y-formara en la juventud un concepto racional y exacto del universo". Si a Albert Einstein le hubieran pedido que diera un concepto racional y exacto del universo, seguramente hubiera soltado una carcajada ante tan imposible y absurda petición [...].”3
\end{abstract}

En otras palabras, los "radicales" tendrían un plan que se iniciaría con el establecimiento en la Constitución del monopolio estatal en materia educativa y, una vez con todo el poder y las condiciones precisas, se declararía abiertamente su carácter socialista. Esto último, además, sería un absurdo de acuerdo con los autores quienes, lejos de analizar el proyecto de "educación socialista” para mostrar sus contradicciones o ambigüedades, 4 se respaldan en una frase especulativa basada, a su vez, en un aparente criterio de autoridad.

Casi una década después, en el año 2000, Rafael Rodríguez López, delegado de la Universidad Autónoma de Guadalajara (UAG), presentó una semblanza histórica de la institución educativa en el Congreso Nacional sobre Historia de la Educación Superior en México. El relato comienza con un contexto más o menos amplio del proceso revolucionario mexicano y su institucionalización, teniendo como eje central el tema educativo y en especial la llamada "educación socialista”:

\footnotetext{
"La naciente institucionalización de la Revolución Mexicana, al principio de los años treinta, se vio asistida muy de cerca por agentes de la Komintern, establecidos en los seis años de relaciones diplomáticas con la Unión Soviética, que aunque ya entonces oficialmente suspendidas, habían sentado las bases para reencauzarla hacia el marxismo-leninismo, comenzando por sustituir la educación libre y laica establecida en la Constitución de 1917 por la educación socialista obligatoria”. 5
}

La radicalización del proceso mexicano, según Rodríguez, tendría como principal causa la influencia de su par soviético y uno de los campos en los que se evidenciaba dicho contubernio era el educativo, particularmente en la

\footnotetext{
3 LOUVIER Calderón, Juan, Ob. cit., p. 20. Cursivas y negritas en el original.

4 YANKELEVICH, Pablo, La educación socialista, México, Departamento de Educación Pública del Estado de Jalisco, 1985.

5 RODRÍGUEZ López, Rafael, "Semblanza histórica de la Universidad Autónoma de Guadalajara", ponencia presentada en el Congreso Nacional sobre Historia de la Educación Superior en México, México, Tijuana, Baja California, 8 de noviembre de 2000, p. 1.
} 
modificación del artículo tercero constitucional. Esto, por otra parte, significaría una validación implícita de la versión original del referido artículo.

Páginas más adelante el argumento de la influencia soviética es llevado al extremo:

“[...] Lázaro Cárdenas [...] pasó jornadas en su finca "Eréndira” de Pátzcuaro en diálogo con altos representantes de la Komintern. [...] Su compromiso internacional, como documentaron especialistas en la materia, fue la comunización [sic] de México que se continuaría por toda América Latina, hasta llegar a constituirse, personalmente, en presidente de la Unión de Repúblicas Soviéticas Socialistas Latinoamericanas". 6

Aunque la afirmación pudiera resultar curiosa -por decir lo menos- para cualquiera con referencias sólidas sobre el periodo, llama la atención que se sostenga en una frase fundada en un criterio de autoridad ambiguo y sin referencia puntual: "como documentaron especialistas en la materia".

Las dos versiones tienen sensibles diferencias: mientras que en la primera se puede inferir un plan de los "radicales", en la segunda éstos sólo aparecieron en la medida que fueron asistidos por sus pares soviéticos; por otra parte, para el texto de la UPAEP, el artículo tercero de 1917 ya era restrictivo, mientras que para el autor de la UAG el problema apareció hasta la reforma de 1934; en tercer lugar, la figura de Lázaro Cárdenas tiene una mayor presencia en la segunda versión como posible promotor de un proyecto continental, mientras que en la primera aparece como la cabeza de un gobierno que promovió un sinsentido.

A pesar de esto, ambas interpretaciones comparten el tema de la presencia estatal en el campo educativo así como de la crítica a los regímenes revolucionarios, especialmente el de Lázaro Cárdenas y su "educación socialista"; también hay coincidencia en la referencia a la Constitución de 1917 y sus subsecuentes reformas; finalmente, hay una insistencia en ambos textos por etiquetar a los revolucionarios como "radicales", "marxistas", "anarquistas", "marxistas-leninistas" "socialistas" y “comunistas" estableciéndolos implícitamente como sinónimos y por tanto, abonando a una ambigüedad útil para los argumentos.

${ }^{6}$ RODRÍGUEZ López, Rafael, Ob. cit., p. 45. 
¿Por qué, al ser interpretaciones diferentes, comparten un sustrato conspirativo?, ¿̇cómo explicarlas en pleno fin de siglo XX e inicio del XXI? Lejos de la casualidad o la anécdota curiosa, detrás de ambos textos están organizaciones católicas secreto-reservadas. La UAG fue fundada a mediados de los años treinta por un núcleo de jóvenes católicos quienes también crearon una agrupación secreta llamada Tecos cuyo objetivo central sería "frenar el avance del comunismo en las universidades". Con el tiempo, este grupo promovió la creación de núcleos similares en otras ciudades de México, siendo su experiencia más exitosa El Yunque, organización que nació en la Universidad de Puebla y que luego se expandió. En los años sesenta los grupos se separaron y en los setenta, el núcleo poblano fundó la UPAEP.

\section{La reacción de antimodernos y perseguidos}

La historia de los Tecos y El Yunque es la historia de una galaxia de organizaciones secretas mexicanas cuyo origen y desarrollo se explica por la adaptación local de la tradición integral intransigente del catolicismo, así como por el escenario conflictivo de la revolución mexicana y sus secuelas, plasmado en el imaginario de numerosos católicos como la "persecución revolucionaria".

La tradición integral intransigente, forjada al calor de la disputa entre la Iglesia católica y los Estados liberales durante la segunda mitad del siglo XIX, se definió a través de tres vías. En primer lugar espacios de formación como el Colegio Pío Latinoamericano fundado en 1858 y la Pontificia Universidad Gregoriana establecida en 1873, ambos dirigidos por miembros de la Compañía de Jesús.7 En segundo término reuniones como el Concilio Vaticano I (18691870) en el que se instituyó la "infalibilidad del papa" y se refrendó el rechazo absoluto a la modernidad y sus derivaciones ${ }^{8}$ y, también, el Concilio Plenario Latinoamericano en Roma al que asistieron 13 arzobispos y 40 obispos (1899) y en el que se discutieron los problemas que enfrentaban las distintas jerarquías

\footnotetext{
7 GARCÍA Ugarte, Marta Eugenia, "La mentalidad católica y la política liberal", Riccardo Cannelli, Nación católica y estado laico. El conflicto político-religioso en México desde la Independencia hasta la Revolución (1821-1914), México, Instituto Nacional de Estudios Históricos de las Revoluciones de México / SEP, 2012, pp. 13-14.

${ }^{8}$ Meses después, en el contexto de la unificación italiana, el beligerante sumo pontífice vivió la pérdida de su poder terrenal y se declaró "prisionero" en El Vaticano, confirmando ante los ojos de los católicos la existencia de un enemigo.
} 
de la región, se analizaron soluciones conjuntas y se reafirmó el pacto de fidelidad al papa. 9 En tercer lugar, las encíclicas como la Quanta cura (1864) que explicitaba el rechazo a la modernidad y a sus diversas expresiones como el liberalismo y el comunismo y que incluía el Syllabus, un listado de conceptos e ideas modernas consideradas errores, ${ }^{10}$ la Aeternes Patris (1879) en la que se reivindicó la filosofía tomista frente al pensamiento moderno ilustrado ${ }^{11}$ y la Rerum Novarum (1891), en la que se hacía un llamado a los católicos para abandonar la disputa política y concentrar sus esfuerzos en el ámbito social. ${ }^{12}$

De esta forma, el integralismo intransigente se erigió como la tendencia hegemónica del pensamiento católico entre el Concilio Vaticano I y el Concilio Vaticano II (1962-1965). El integralismo es la cualidad del catolicismo de estar presente en todos los aspectos de la vida y no sólo en prácticas culturales. De acuerdo con Roberto Blancarte quien sigue a Poulat, el integralismo tiene un carácter social porque forma parte de la vida pública, tiene cierto signo popular y exige una gran movilización de fuerzas católicas y es romano, porque asume al papa como la cabeza y el corazón del catolicismo. ${ }^{13}$ En consecuencia, se relaciona con "el pensamiento de reconquista o de cristiandad; [...] se dirigía a

9 ALEJOS Grau, Carmen José, "La evangelización en los concilios celebrados en América Latina entre 1899 y 1957”, Annuarium Historiae Conciliorum, no. 44, 2012, pp. 244, 246; DE ROUX, Rodolfo R., "La romanización de la Iglesia católica en América Latina: una estrategia de larga duración”, Pro-Posições, Faculdade de Educação- Universidade Estadual de Campinas, vol. 25, no.1, enero-abril, 2014.

10 Pío IX, "CARTA ENCÍCLICA QUANTA CURA DEL SUMO PONTÍFICE PÍO IX Sobre los principales errores de la época”, <http://www.statveritas.com.ar/Magisterio\%20de\%2ola\%20Iglesia/CARTA_ENCICLICA_QU ANTA_CURA.pdf $>$. [Consulta: 4 de junio de 2015.]

11 León XIII, "EPÍSTOLA ENCÍCLICAAETERNI PATRISDEL SUMO PONTÍFICELEÓN XIIISOBRE LA RESTAURACIÓN DE LA FILOSOFÍA CRISTIANACONFORME A LA DOCTRINA DE SANTO TOMÁS DE AQUINO, 1879, < http://w2.vatican.va/content/leoxiii/es/encyclicals/documents/hf_l-xiii_enc_04081879_aeterni-patris.html $>$. [Consulta: 4 de junio de 2015.]

${ }^{12}$ León XIII, "CARTA ENCÍCLICA RERUM NOVARUM DEL SUMO PONTÍFICE LEÓN XIII SOBRE LA SITUACIÓN DE LOS OBREROS”, 1891, < http://www.vatican.va/holy_father/leo_xiii/encyclicals/documents/hf_l-

xiii_enc_15051891_rerum-novarum_sp.html >. [Consulta: 6 de junio de 2014.]

13 BLANCARTE, Roberto, "La Doctrina Social del Episcopado católico mexicano", Roberto BLANCARTE (comp.), El pensamiento social de los católicos mexicanos, México, Fondo de Cultura Económica, 1996, pp. 26-27. 
la formación de católicos de tiempo completo que podían y debían incidir en la vida total de la nación para restaurar el orden social cristiano."14

Por su parte, la intransigencia hace referencia al rechazo del liberalismo como ideología dominante por parte de la Iglesia católica y, por ende, establece una imposibilidad de hacer concesiones doctrinarias. ${ }^{15}$ En ese sentido, reivindica lo que considera las tres notas distintivas del catolicismo: inmutabilidad, intangibilidad e integralidad. Por lo anterior, su legitimidad no depende de argumentos teóricos o de una base social, sino de la doctrina misma. ${ }^{16}$

En tercer lugar, como respuesta al catolicismo que buscaba conciliar con el liberalismo, aproximadamente en 1890 surgió en España un movimiento denominado integrismo que abrevó claramente del integralismo y que tuvo como principal inspiración el Syllabus. Posteriormente, el papa Pío X retomó el término para hacer referencia a los "católicos íntegros" que combatían por cualquier medio la apertura política y social del catolicismo ante la modernidad. Así, llevado al extremo, el integrismo promovió la vigilancia, denuncia y castigo de católicos a manos de otros católicos con la justificación de proteger a la religión y la Iglesia de los "errores modernos" ${ }^{17}$

En otras palabras, como sugiere Lila Caimari siguiendo a Émile Poulat, los dos papados que cubrieron más de la mitad del siglo XIX -Pío IX y León XIII- pasaron del rechazo radical y el aislamiento ante la "amenaza moderna", a la ofensiva por la vía social sin dejar de condenar al enemigo y sus varias caras, a saber: liberalismo y comunismo-socialismo. ${ }^{18}$ Durante ese trayecto se volvió urgente la reorganización de la estructura eclesiástica en torno al papa para consolidar la concentración "del poder dogmático, del poder doctrinario y del

\footnotetext{
14 ASPE Armella, María Luisa, La formación social y política de los católicos mexicanos. La Acción Católica Mexicana y la Unión Nacional de Estudiantes Católicos, 1929-1958, México, Universidad Iberoamericana / Instituto Mexicano de Doctrina Social Cristiana, 2008, p. 25. 15 ASPE, Ob. cit., p. 25.

16 POULAT, Émile, Intégrisme et catholicisme intégral. Un réseau secret international antimoderniste: la "Sapinière" (1909-1921), París, Casterman, 1969, p. 9.

17 POULAT, Ob. cit., pp. 78-79.

18 CAIMARI, Lila, Perón y la Iglesia católica. Religión, Estado y sociedad en la Argentina (1943-1955), Buenos Aires, Emecé, 2010, p. 40.
} 
poder disciplinario"19, es decir, romanizar a la Iglesia y a partir de eso recristianizar a las sociedades.

Es importante hacer dos acotaciones sobre el pensamiento integral intransigente. Primero, que fue construido por los católicos de numerosas regiones, destacando los europeos, y al mismo tiempo fue asimilado y adaptado a los distintos contextos regionales y locales. De ahí que, aunque se encuentren los rasgos distintivos del código en discursos y acciones de grupos e individuos, también muestren particularidades propias de sus horizontes históricos.

En segundo término, a pesar de que este código antimoderno fuera binario y sumamente rígido en sus postulados, tenía la ventaja de un trasfondo conspirativo que lo dotaba de flexibilidad. En otras palabras, si bien el enemigo principal era la modernidad, se partía del supuesto que existía un enemigo histórico del catolicismo y que adoptaba diferentes caras. De esta forma, casi cualquier sujeto, colectividad, proceso o coyuntura podía ser integrado al listado de enemigos sin mayores explicaciones pues la coherencia y veracidad del código no dependían de las pruebas, en primera instancia, sino de la fe en las autoridades que lo promulgaban. No importaban las diferencias ideológicas entre liberales, comunistas y socialistas, ni las distancias temporales o espaciales, pues al final todo formaba parte de un plan para destruir a la civilización cristiana.

Es decir que el lugar social de cada sujeto, la adaptabilidad del código y los contextos históricos cambiantes produjeron una multiplicidad de experiencias en torno al integralismo intransigente. Por eso, aunque se pueden encontrar rasgos ideológicos comunes en distintas organizaciones e individuos, al mismo tiempo presentan diferencias sustanciales en prácticas y discursos, llegando a disensos importantes especialmente en momentos de alta conflictividad.

Lo anterior fue patente entre 1914 y mediados de los años treinta, etapa en la que católicos y regímenes revolucionarios mexicanos disputaron su papel

19 DI STEFANO, Roberto; ZANATTA, Loris, Historia de la Iglesia argentina. Desde la Conquista hasta fines del siglo XX, Buenos Aires, Grijalbo-Mondadori, 2000, p. 332. 
hegemónico en la vida pública. Por supuesto, al haber sido confinados desde el prinicipio al bando de la "reacción" y por tanto ser considerados enemigos de la revolución, ${ }^{20}$ muchos católicos definieron y recordaron este periodo como la "persecución revolucionaria". ${ }^{21}$ Sin restar mérito al sentido literal de la oración, pues existieron numerosos ejemplos de excesos contra los católicos, ${ }^{22}$ lo cierto es que este periodo se definió mayoritariamente por la confrontación con un saldo positivo para el Estado y por momentos clímax, como la promulgación en 1917 de una nueva Constitución, en la que se condensaban las reivindicaciones liberales de su antecesora y las demandas de las facciones populares de la revolución, destacándose algunos artículos por su fuerte componente anticlerical,23 la expulsión del delegado apostólico en 1923 bajo el argumento de que representaba la injerencia de una nación extranjera, por la llamada "guerra cristera" entre 1926 y 1929 que constituyó el mayor enfrentamiento armado entre los bandos, así como el proyecto de la "educación socialista" puesto en práctica a partir de 1934 bajo el gobierno del general Lázaro Cárdenas (19341940).

Al mismo tiempo, como se señaló en la introducción, una serie de símbolos y prácticas introdujeron en el escenario mexicano el referente de la

${ }^{20}$ En 1913 el gobierno de Francisco I. Madero terminó con un golpe de estado cuyos saldos fueron el asesinato del presidente, la instauración de un nuevo régimen encabezado por el general Victoriano Huerta y la emergencia de ejércitos populares con reivindicaciones variopintas pero unificados por el rechazo al huertismo. Esto es relevante pues un sector de los católicos apoyó el golpe y respaldó económicamente al régimen de Huerta, lo que derivó en una acusación de traición por parte de los revolucionarios contra todos los católicos. O'DOGHERTY Madrazo, Laura, De urnas y sotanas. El Partido Católico Nacional en Jalisco, México, Consejo Nacional para la Cultura y las Artes / UNAM, 2001.

${ }^{21}$ GUTIÉRREZ Casillas, José, Jesuitas en México durante el siglo XX, México, Ed. Porrúa, 1981, pp. 76-82; LEDIT, Joseph, El frente de los pobres, México, Ediciones Spes, 1955.

${ }^{22}$ En algunos estados gobernados por generales revolucionarios, como Tabasco, se permitieron experimentos radicales con un fuerte componente anticlerical. MARTÍNEZ Assad, Carlos, $E l$ laboratorio de la revolución. El Tabasco garridista, Siglo XXI Editores, México, 1979.

${ }^{23} \mathrm{El}$ artículo $3^{\circ}$, que establecía la educación laica y prohibía que las corporaciones religiosas o ministros se encargaran de escuela alguna; el $5^{\circ}$ que entre otros puntos no permitía el establecimiento de órdenes monásticas; el artículo 13 que prohibía los tribunales especiales; el artículo 24 que establecía la libertad de credo, pero confinaba el culto a los templos; el artículo 27 que prohibía a las iglesias "adquirir, poseer o administrar bienes raíces" y de hecho, aquellos que tuvieran pasarían al dominio de la Nación; el artículo 55 que anulaba la posibilidad de que un ministro de algún culto accediera al cargo de diputado; y finalmente, el 130 que confirmaba la separación de la Iglesia y el Estado, dando a éste último la potestad de vigilar el culto, limitar el número de ministros y exigir que éstos fueran mexicanos, además de anular sus derechos políticos. "Constitución Política de los Estados Unidos Mexicanos", 5 de febrero de 1917, <https://www.juridicas.unam.mx/legislacion/ordenamiento/constitucion-politica-de-losestados-unidos-mexicanos $>$. [Consulta: 22 de abril de 2017] 
revolución bolchevique. Por ejemplo, en 1919 se fundó el Partido Comunista Mexicano (PCM) que, si bien no constituyó una fuerza política de gran peso, llevaba en el nombre una carga simbólica fundamental;24 a partir de 1920 algunas facciones radicales orillaron al grupo en el poder a profundizar diversas medidas y en ese ambiente aparecieron claras aluciones a los "logros" del proceso revolucionario del otro lado del Pacífico, especialmente en debates parlamentarios; 25 en 1924 el gobierno mexicano fue el primero de América en reconocer a la Unión de Repúblicas Socialistas Soviéticas (URSS) y, aunque seis años después rompería relaciones diplomáticas, sentaría un importante precedente; finalmente, durante el gobierno de Cárdenas, además de la educación socialista, se permitió que el PCM saliera de la clandestinidad y se profundizaron las reformas en materia agraria y obrera con miras a corporativizar a las llamadas "fuerzas vivas" de la revolución, sin mencionar la política de nacionalizaciones que incluyó la expropiación del petróleo en 1938 o el asilo al revolucionario León Trotsky en 1936 y a contingentes de republicanos españoles.

Hasta este punto no es dificil suponer que numerosos católicos, especialmente los que habían tenido alguna militancia política, lograron intercalar la tradición integral intransigente con un sentimiento de persecución y agravio por distintas vías -política, militar y jurídica-, así como con las numerosas "pruebas" que ofrecían los regímenes locales, para concluir que existía algún vínculo más o menos fuerte entre los procesos revolucionarios mexicano y ruso. Pero si alguna duda cabía en el razonamiento, se podía disipar con el criterio de autoridad que poseían los prelados y el sumo pontífice.

Por ejemplo, en septiembre de 1932 en la encíclica Acerba Animi, el papa Pío XI comparó el caso mexicano con la situación rusa:

\begin{abstract}
"Hemos querido resumir brevemente los puntos principales de la grave condición impuesta a la Iglesia de México, porque los amantes del orden y la paz de los pueblos, viendo cómo una persecución sin precedentes no es diferente, especialmente en algunos Estados, de aquella desatada en la infeliz región de
\end{abstract}

\footnotetext{
${ }^{24}$ CARR, Barry, La izquierda mexicana a través del siglo XX, México, Ediciones Era, 1996. 25 URÍAS, Ob. cit.
} 
Rusia, lleven, de esta inicua coincidencia de intentos, nuevo ardor para encauzar la llama subversora de otro orden social". ${ }^{26}$

Dos años después, en respuesta a la modificación del artículo tercero de la Constitución y por tanto a la "educación socialista", monseñor Leopoldo Ruiz arzobispo de Morelia y delegado apostólico mexicano exiliado en Estados Unidos declaró a través de un desplegado:

\begin{abstract}
"Abiertamente nos oponemos al socialismo revolucionario de México, porque, como ya dijimos en nuestra instrucción del 12 del actual, dicho socialismo claramente se ha mostrado ateo en religión, comunista en economía política y materialista en sociología, pretendiendo disfrazar esos gravísimos y trascendentales errores con las equívocas palabras de desfanatizar y desvanecer prejuicios". ${ }^{27}$
\end{abstract}

La comparación explícita y la condena hechas por jerarcas católicos evocaban la postura del integralismo intransigente ante la modernidad y sus diversas caras, además de reforzar el "juego de espejos" al que hace referencia Urías en el artículo citado, "confirmando" ante la feligresía que la revolución mexicana tenía un fuerte componente bolchevique.

Y si aún después de esto se mantenía cierto margen de incredulidad, a puerta cerrada circulaban panfletos e informes fabricados que eran promovidos como documentos firmados por el "Servicio Confidencial Reservado de la IIIa Internacional Comunista de Moscú” y robados al gobierno mexicano:

\begin{abstract}
"En acuerdo especial celebrado con el Señor Presidente de la República, me encargó expresar a usted [se refiere a Hernán Laborde secretario general del PCM], lo siguiente [...]. El Señor Arturo H. Villegas entregará a usted, semanariamente la cantidad de $\$ 2,000.00$ (dos mil pesos) para ayuda de sus gastos de propaganda, teniendo cuidado de atacar a nuestro Gobierno para desorientar a las burguesías tanto nacional como extranjera especialmente la norteamericana. Deben provocarse y fomentarse todas las huelgas que más sea posible [...]. Debemos combatir todas las religiones conocidas, muy principalmente la Protestante y la Romana Católica [...]". ${ }^{28}$
\end{abstract}

26 Pío XI, "ACERBA ANIMI. ENCYCLICAL OF POPE PIUS XI ON PERSECUTION OF THE CHURCH IN MEXICO TO OUR VENERABLE BROTHERS OF MEXICO, THE ARCHBISHOPS, BISHOPS, AND ORDINARIES IN PEACE AND COMMUNION WITH THE APOSTOLIC SEE", 1932, <https://w2.vatican.va/content/pius-xi/en/encyclicals/documents/hf_pxi_enc_29091932_acerba-animi.html $>$. [Consulta: 6 de junio de 2014.] Traducción hecha por el autor.

${ }^{27}$ RUIZ, Leopoldo, “A LOS CATÓLICOS MEXICANOS”, 30 de diciembre de 1934, San Antonio, Texas, Archivo Histórico del Arzobispado de México, Fondo E, Sección S.a., Caja 85, Expediente 1, f. 1. El documento es un desplegado hecho por el arzobispo de Morelia y delegado apostólico mexicano exiliado en Estados Unidos.

28 "COMITÉ EJECUTIVO EPISCOPAL. Circular No. 4", 23 de marzo de 1935, México, D.F., Archivo Histórico de la Arquidiócesis de Guadalajara, México, Sección Gobierno, Serie 
Con esto, además de minimizar las posibilidades de duda entre los creyentes, se volvía al fundamento conspirativo del integralismo intransigente, erigiéndose como una forma viable para combatir lo que se percibía como otra conspiración moderna contra la civilización cristiana.

De nuevo se debe señalar que el proceso de interpretación no era unidireccional sino fluctuante entre seglares y clérigos y variante en función de los diversos contextos, generando una considerable multiplicidad de lecturas y experiencias.

\section{Los grupos secretos y su visión conspirativa}

Las facciones revolucionarias supeditaron en todas las dimensiones posibles a la Iglesia católica y plasmaron en la Constitución una idea de nación distante al orden social cristiano ansiado por los católicos militantes. ${ }^{29}$ Durante ese proceso y especialmente a partir de 1917, la actitud de los católicos políticamente activos pasó de la reacción defensiva a la ofensiva por lo que cobraron relevancia tanto la experiencia acumulada en las luchas decimonónicas como la traída por los sacerdotes europeos y la de sus pares locales formados en el viejo continente. $3^{30}$

Dentro de este amplio universo de seglares y clérigos militantes, algunos optaron por continuar sus actividades en secreto como medida de protección, pero dicha condición había sido condenada en la encíclica Humanum Genus de $1884^{31}$ por considerarla propia de la masonería. En consecuencia, no se hablaba de secreto sino de reserva, es decir, una condición en la que no se publicita la pertenencia al grupo ni las acciones del mismo ante el público en general incluyendo a otros católicos-, pero siempre se rinde cuentas a un asesor

Religiosos, Jesuitas, Años 1950-1958, Expediente 10, Caja 3, Correspondencia del Señor Orozco y Jiménez.

29 AGUIRRE Cristiani, María Gabriela, "Entre revolucionarios y católicos: un proyecto de nación, 1913-1917", Yves SOLÍS; Franco SAVARINO (coords.), El anticlericalismo en Europa y América Latina. Una visión transatlántica, México, INAH / CONACULTA / Universidad Católica Portuguesa-Centro de Estudios de Historia Religiosa, 2011, pp. 155-171.

30 Ejemplo de esto fue la creación en 1913 de la Asociación Católica de la Juventud Mexicana por el sacerdote jesuita Bernardo Bergöend.

${ }^{31}$ León XIII, "Carta encíclica Humanum Genus del sumo pontífice León XIII sobre la masonería y otras sectas" [en línea], 1884, <http://es.catholic.net/op/articulos/2509/humanumgenus.html>. [Consulta: 6 de junio de 2014.] 
eclesiástico -sacerdote u obispo- que vigila y sanciona el quehacer de la organización.

Muy pronto, lo que se mostró como una herramienta útil de protección ante la "persecución revolucionaria", derivó en una forma particular de la militancia política de los católicos que implicó la sofisticación de mecanismos de reclutamiento, formación y organización, así como una serie de disputas por la hegemonía al interior del campo católico.

En 1915 fue fundada la Unión de Católicos Mexicanos (UCM) o simplemente la "U”. Esta organización secreto-reservada creció numérica y territorialmente con éxito hasta que fue disuelta al final de la guerra cristera en 1929,32 durante la cual promovió otra agrupación denominada Brigadas Femeninas Juana de Arco.33 Buena parte de los miembros de la "U" nutrieron el contingente de católicos descontentos por la negociación entre algunos obispos y el régimen que terminó el conflicto cristero, por lo que continuaron su militancia secreta. Durante el primer lustro de los años treinta, el ingeniero Manuel Romo de Alba fundó Las Legiones, nueva agrupación que heredó la experiencia de la "U" y potenció su beligerancia. Esto último no fue bien visto por los jerarcas católicos que promovieron el modus vivendi con el Estado, así que comisionaron a sacerdotes jesuitas para que desactivaran a los legionarios. El éxito de los jesuitas derivó en la creación de La Base, una gran organización secreto-reservada que había renunciado a los atentados y la confrontación directa para promover la implantación del "orden social cristiano" a través de un movimiento de masas pacífico y la consecuente toma del poder político. Por lo anterior, hacia los años cuarenta, La Base impulsó una cara pública que se conocería como Unión Nacional Sinarquista (UNS). 34

\footnotetext{
${ }^{2}$ SOLÍS, Yves, "Asociación espiritual o masonería católica: la U”, Istor. Revista de historia internacional, Centro de Investigación y Docencia Económicas, No. 33, verano, 2008, año 9, pp. 121-137; SOLÎS, Yves, "El origen de la ultraderecha en México: la "U"”, El Cotidiano. Revista de la realidad mexicana actual, Universidad Autónoma Metropolitana - Azcapotzalco, no. 149, mayo-junio, 2008, vol. 23, pp. 25-57.

33 MEYER, Cristiada, p. 121; VACA, Agustín, Los silencios de la historia: las cristeras, México, El Colegio de Jalisco, 1998, p. 242; GONZÁLEZ, Fernando M., Matar y morir por Cristo Rey. Aspectos de la cristiada, México, Instituto de Investigaciones Sociales - UNAM / Plaza y Valdés Editores, 2001, pp. 32, 135.

34 ORTOLL, Servando, "Las Legiones, La Base y el Sinarquismo. ¿Tres organizaciones distintas y un solo fin verdadero? (1929-1948)", Rodolfo MORÁN, (comp.), La política y el cielo.
} 
De forma paralela, entre 1934 y 1935 al occidente de México, surgió un grupo juvenil secreto-reservado cuya principal misión era "frenar el avance del comunismo". En efecto, en el contexto de la disputa por la educación socialista se gestó un movimiento heterogéneo al interior de la Universidad de Guadalajara, cuya finalidad era evitar que se implementara la reforma en la institución educativa. De dicho movimiento se desprendió un ala católica radical encabezada por Carlos Cuesta Gallardo y los hermanos Ángel y Antonio Leaño Álvarez del Castillo, todos representantes de familias de la élite local y antiguos estudiantes del Instituto de Ciencias de Guadalajara fundado y dirigido por sacerdotes jesuitas. 35 La facción se denominó Federación de Estudiantes de Jalisco (FEJ).

Luego de meses de confrontación con otros grupos juveniles y con el gobierno estatal, el conflicto escaló hasta que cayeron los primeros muertos. En ese punto, el gobierno federal decidió ceder un poco para desactivar una posible nueva rebelión cristera y dio el permiso para que se fundara la Universidad Autónoma de Occidente, luego llamada Universidad Autónoma de Guadalajara, donde el núcleo estudiantil dirigente que había pertenecido a Las Legiones, creó un grupo secreto-reservado conocido como los Tecos.

Dos décadas después de su fundación, en el marco de un proceso de expansión, los Tecos establecieron un núcleo similar en la ciudad de Puebla al oriente de México. Dicho grupo, liderado por un joven llamado Ramón Plata Moreno, adoptó el nombre de El Yunque. Al igual que sus antecesores, los

\footnotetext{
Movimientos religiosos en el México contemporáneo, México, Universidad de Guadalajara, 1990, p. 74; SERRANO Álvarez, Pablo, "La 'batalla del espíritu': el movimiento sinarquista en el Bajío Mexicano (1934-1951)", Rodolfo MORÁN, (comp.), La política y el cielo. Movimientos religiosos en el México contemporáneo, México, Universidad de Guadalajara, 1990, pp. 124-125. 35 MENDOZA Cornejo, Alfredo, Organizaciones y movimientos estudiantiles en Jalisco de 1900 a 1937, México, Universidad de Guadalajara, 1989, p. 226; PALOMERA, Esteban J., La obra educativa de los jesuitas en Puebla, 1578-1945, México, Universidad Iberoamericana / Instituto Oriente / Benemérita Universidad Autónoma de Puebla, 1999, p. 352; RIVERA Ortiz, Mario Héctor, El estudiantado, una nueva clase social. Acontecimientos cardinales en la historia del estudiantado de la Universidad de Guadalajara en el periodo 1933-1991, México, Edición del autor, 2007, pp. 56-58; GONZÁLEZ, Fernando M., "Los orígenes y el comienzo de una universidad católica: sociedades secretas y jesuitas", Historia y Grafía, Universidad Iberoamericana, No. 20, 2003, p. 170.
} 
yunquistas se expandieron logrando instalarse con relativo éxito en la Ciudad de México. ${ }^{36}$

Como se dijo, lo que nació como una táctica útil derivó paulatinamente en una forma de militancia política en la que se establecieron prácticas e ideas que luego fueron transmitidas: su estructura era piramidal y estaba conformada por células autónomas que no se conocían entre sí, lo que blindaba a los distintos niveles de la agrupación en caso de detenciones; para actuar, promovían grupos públicos que hacían las veces de fachada y espacios de reclutamiento; los posibles reclutas eran observados y puestos a prueba sin que lo supieran, para luego integrarlos con juramentos de obediencia y secrecía de por medio; siempre había vigilancia y asesoría de algún sacerdote, especialmente jesuita, y permanente contacto con el obispo de la diócesis; y todo se articulaba en torno a la idea de implantar el "reinado de Cristo en la tierra", fórmula que solía ir acompañada de la "implantación del orden social cristiano".37

Resulta central señalar que, además de algunos seglares, los principales vehículos de transmisión de experiencias y conocimientos fueron los clérigos y obispos que fungieron como asesores de las organizaciones, especialmente los miembros de la Compañía de Jesús. ${ }^{38}$ En efecto, a pesar de que no todos los miembros de la institución eclesiástica estaban de acuerdo con la existencia de agrupaciones secreto-reservadas e incluso llegaron a condenarlas públicamente, 39 muchos otros las promovían y protegían. Incluso había

${ }_{36}$ DELGADO, Álvaro, El Yunque. La ultraderecha en el poder, México, Ed. Grijalbo, 2003; SANTIAGO Jiménez, Mario Virgilio, "Entre el secreto y las calles. Nacionalistas y católicos contra la 'conspiración de la modernidad': El Yunque de México y Tacuara de Argentina (19531964)", tesis de doctorado en Historia Moderna y Contemporánea, México, Instituto de Investigaciones Dr. José María Luis Mora, 2016.

37 SANTIAGO Jiménez, Mario Virgilio, "Entre”, Ob. cit..

${ }^{38}$ MEYER, Jean, Cincuenta años de radicalismo: la Iglesia católica, la derecha y la izquierda en América Latina, México, Instituto Mexicano de Doctrina Social Cristiana, 1990.

MEYER, Jean, "Disidencia jesuita", Nexos [en línea], México, 1 de diciembre, 1981.

39 En enero de 1923 el gobierno federal expulsó del país al delegado apostólico monseñor Ernesto Filippi lo que benefició a la "U" pues éste había sido comisionado por el papa Pío XI para disolver la organización reservada. SOLÍS, Yves, "Asociación espiritual o masonería católica: la U”, Istor. Revista de historia internacional, Centro de Investigación y Docencia Económicas, No. 33, verano, 2008, año 9, pp. 122-123; SOLÍS, Yves, "El origen de la ultraderecha en México: la "U"”, El Cotidiano. Revista de la realidad mexicana actual, Universidad Autónoma Metropolitana - Azcapotzalco, no. 149, mayo-junio, 2008, vol. 23, p. 28. 
ocasiones en que un mismo sacerdote u obispo emitía condenas en público y asesoraba a un núcleo en secreto. 40 Todo esto, sumado a las militancias múltiples de algunos seglares -es decir, la participación simultánea en organizaciones secreto-reservadas y públicas-, también provocó un "juego de espejos" al interior del universo católico.

El respaldo institucional, aunque parcial, fue la clave para que los militantes de las organizaciones secreto-reservadas, especialmente de las Legiones, La Base, los Tecos y El Yunque, articularan el pensamiento integral intransigente, la "persecución revolucionaria" y la revolución rusa en torno a un corpus conspirativo recién importado que se podía sintetizar en la idea de una conspiración judeo-masónico-comunista contra la civilización cristiana y que tendría como documento canónico un texto apócrifo llamado Los Protocolos de los Sabios de Sión, probablemente escrito a fines del siglo XIX y atribuido a la policía zarista. El texto, que fue adaptado y distribuido por Europa y América con gran éxito, simula ser el conjunto de actas del primer Congreso Sionista reunido en Basilea en septiembre de 1897, en el que un conjunto de rabinos darían cuenta de las acciones que se han llevado a cabo para destruir a la civilización cristiana: conspiraciones, promoción de ideologías, revoluciones, golpes de Estado, confrontación de grupos sociales, etc. ${ }^{41}$ No sobra señalar que, al ser ofrecido y explicado por sacerdotes, el texto era asimilado y aceptado por diversos creyentes con la certeza que otorga el criterio de autoridad, por lo que lejos de presentarse como una farsa, Los Protocolos cumplirían el papel de "pruebas". 42

Siguiendo esa lógica, algunos pasajes funcionan como claves de lectura, por ejemplo, la decimoquinta acta hace referencia al proceso bolchevique de la siguiente forma: "Tal era hasta estos últimos tiempos la autocracia rusa, nuestro único enemigo serio en el mundo, así como el Papado.” Y tras confirmar la

40 Ejemplo de esto fue el arzobispo de Guadalajara José Garibi Rivera quien condenó públicamente a Las Legiones pero protegió a los Tecos. SANTIAGO Jiménez, Mario Virgilio, "Entre", Ob. cit., pp. 89-92.

${ }^{41}$ LVOVICH, Daniel, Nacionalismo y Antisemitismo en la Argentina, Buenos Aires, Ediciones B, 2003; COHN, Norman, El mito de la conspiración judía mundial. Los Protocolos de los Sabios de Sión, Madrid, Alianza Editorial, 2010.

42 Este mecanismo nos remite al documento apócrifo citado en la segunda parte del presente texto sobre un supuesto acuerdo entre el gobierno mexicano y un líder del PCM para desestabilizar al país a cambio de recursos económicos. 
participación de la conspiración en la instauración del comunismo soviético, el mismo texto anuncia el plan de expansión: "Cuando empecemos a reinar con ayuda de golpes de Estado preparados por todas partes para un mismo día, después de la confesión definitiva de la nulidad de todos los Gobiernos existentes (tal vez pasará un siglo antes que esto suceda), trataremos de que no haya complots contra nosotros." 43

De acuerdo con uno de los líderes y miembros de la primera generación de El Yunque, el libro fue traído a México en los años treinta por el sacerdote jesuita Julio Vértiz, quien llegó como enviado del falangismo español44 y fue rápidamente replicado y asimilado por otros clérigos, especialmente aquellos cercanos a los grupos secreto-reservados. De hecho, entre los asesores de los Tecos y El Yunque habría por lo menos dos jesuitas fuertemente influenciados por la idea de la conspiración judeo-masónico-comunista: Manuel Figueroa Luna, 45 quien de hecho asistió la fundación del núcleo poblano, y Joaquín Sáenz Arriaga. 46

Durante los siguientes años, los programas de formación de tecos $\mathrm{y}$ yunquistas integraron nuevos materiales de lectura en la misma frecuencia conspirativa que iban desde reflexiones teológicas hasta "análisis históricos". 47

43 Los Protocolos de los Sabios de Sión. Los peligros judío-masónicos, México, Berbera Editores, 2005, pp. 71-72.

44 Entrevista a Manuel Antonio Díaz Cid, realizada por Mario Virgilio Santiago Jiménez, Puebla, México, 20 de febrero de 2012. Según Ricardo Pérez Montfort, Vértiz estuvo exiliado en Estados Unidos hasta 1938 "a sugerencia de Cárdenas y del propio arzobispo de México", luego regresó como representante del régimen franquista. PÉREZ Montfort, Ricardo, Hispanismo y Falange: los sueños imperiales de la derecha española y México, México, Fondo de Cultura Económica, 1992, p. 141.

45 Nació en 1899 en Guadalajara. Se ordenó en la Compañía en 1933. Formado en Roma, Barcelona y los Estados Unidos, Figueroa era considerado un buen estudiante y profesor. Leía y escribía griego, latín, italiano y francés, además de conocer el inglés y el alemán. Entre 1936 y 1940 fue padre espiritual y profesor del grupo de Universitarios en el Instituto de Ciencias en Guadalajara. Posteriormente fue padre espiritual, ministro y procurador en el Instituto Oriente de Puebla hasta 1945, año en que regresó a Jalisco para ser rector del Instituto de Ciencias hasta 1952, cuando retornó a Puebla. Informe, México, s/f, exp. Manuel Figueroa Luna, AHPMCJ.

46 Nació en 1899. Ingresó a la Compañía en 1916. Estudió en Estados Unidos, España y Nicaragua. Fue ordenado sacerdote en 1930. Se caracterizó por su cercanía con los jóvenes así como por mantener posturas radicales e intransigentes. Esto último lo llevó a cuestionar el Concilio Vaticano II hasta defender una postura "sedevacantista", es decir, afirmar que el Papa era parte de un complot contra la Iglesia católica y por ende debía ser desconocido. Fue excomulgado por estas afirmaciones. RIUS Facius, iExcomulgado! Trayectoria y pensamiento del Pbro. Dr. Joaquín Sáenz Arriaga, México, Costa-Amic Editores, 1980.

47 Entrevista a Manuel Antonio Díaz Cid, realizada por Mario Virgilio Santiago Jiménez, Puebla, México, 20 de febrero de 2012. 
Uno de estos textos era El judío. La teología en defensa del catolicismo del sacerdote Julio Meinvielle, $4^{8}$ publicado en Buenos Aires en 1936 -durante un importante auge del conservadurismo en el país sudamericano- y 23 años después en México. El autor, desde los años treinta, desarrolló una línea de pensamiento anclada en la obra de Santo Tomás, el integralismo intransigente y un furibundo antisemitismo que le valió cierta fama en los círculos internacionales donde circulaba la idea de la conspiración. Esto último es relevante porque a partir de fines de los años cincuenta y durante los sesenta, con patrocinio de la UAG, Meinvielle visitó México en varias ocasiones para ofrecer conferencias a los jóvenes militantes de las organizaciones secretoreservadas. 49

En ese sentido, El judío ofrece un amplio abanico de elementos para una interpretación en clave conspirativa: "Los hechos nos van diciendo que el proceso de descristianización, iniciado por el Humanismo del Renacimiento y de la Revolución Francesa, y que culmina ahora en la Revolución Soviética, es un proceso típico de judaización del mundo [...]”.50 Para refrendar lo anterior, Meinvielle aborda diversos pasajes revolucionarios y refiere a numerosos judíos como promotores, por ejemplo, apunta que un sujeto llamado Jacobo Schiff financió a Trotsky en 1917. ${ }^{1}$

Otro material de formación era Derrota Mundial. Supracapitalismo y marxismo en pareja globalizadora de Salvador Borrego, ${ }^{52}$ publicada en México por primera vez en 1953 y con amplia circulación pública en la actualidad. En

\footnotetext{
48 Nació en Buenos Aires en 1905 y fue ordenado sacerdote en 1930. Con estudios en Roma y un doctorado en teología y filosofía, se caracterizó por una constante actividad pública que no se restringió a los muros de las iglesias, pues se erigió como un prolífico autor de textos, un polemista en diversos espacios del nacionalismo católico argentino y un asesor o incluso mentor de varias generaciones de jóvenes militantes de la derecha católica argentina como los integrantes del Movimiento Nacionalista Tacuara. SANTIAGO Jiménez, Mario Virgilio, "Entre", Ob. cit.

49 SANTIAGO Jiménez, Mario Virgilio, "Julio Meinvielle, tacuaras, los Tecos y El Yunque contra la "infiltración roja” en México y Argentina”, Cahier des Amériques latines, París, Institut des hautes études de l'Amérique latine-université Sorbonne Nouvelle-Paris 3, no. 79, 2015/2, pp. 55-74.

50 MEINVIELLE, Julio, El judío. La teología en defensa del catolicismo, México, Ediciones R.T.S.A., 1959, p. 75 .

${ }^{51}$ MEINVIELLE, Julio, Ob. cit., p. 93.

52 Nació en la Ciudad de México en 1915. Participó en numerosos periódicos de circulación nacional y local de donde obtuvo información para escribir varios de sus numerosos libros. Se ha declarado públicamente simpatizante del nacionalsocialismo, anticomunista y nacionalista.
} 
dicho libro se argumenta la existencia de una conspiración milenaria que, hacia el siglo XIX, constituyó dos grandes tendencias revolucionarias, el comunismo y el capitalismo, y que tuvo un punto clímax con el triunfo de los aliados en 1945 cuando ambas líneas se aliaron para derrotar a un gran movimiento nacionalista gestado en Alemania. Mucho más extenso que Los Protocolos y El judío, este material ofrece una narrativa más fluida, casi a manera de crónica periodística, acompañada de múltiples datos verídicos y falaces e imágenes que podrían resultar atractivos para un público más amplio.

Aunque no hay referencias a México, igual que los dos materiales anteriores, Derrota mundial presenta pasajes fácilmente asimilables a la experiencia local, por ejemplo: "Que en un pueblo sin religión se combata una nueva religión, parece explicable; pero que un pueblo religioso surja un régimen intransigentemente antirreligioso, es un fenómeno de orígenes extraños al pueblo mismo. Y tal fue lo que sucedió en Rusia."53

Un cuarto material de formación de tecos y yunquistas fue La Gran Conspiración Judía de Traian Romanescu publicada por primera vez en 1956 en español. En dicho texto se hace un amplio recorrido por la supuesta historia de la referida conspiración diseñada y ejecutada por los judíos contra la civilización cristiana con la novedad de que hay capítulos específicos para los casos español, estadounidense y árabe, en una especie de ejercicio de actualización del diagnóstico en el que, sin duda, llama la atención que se haga una reivindicación del Islam como un nuevo objetivo del judaísmo. Además, a partir de la edición de 1961, el libro agrega un apartado sobre "La conspiración en Iberoamérica" en la que se argumenta que el "mal judaico" ha atravesado con éxito Europa y ha llegado a las "antiguas colonias", término que sin duda evidencia una postura hispanista conservadora. ${ }^{54}$ Luego se listan algunas "pruebas" correspondientes a cada país de la región y en el caso de México, se señala lo siguiente: "Durante una de las más enconadas persecuciones religiosas, bajo el régimen de Plutarco Elías Calles, estuvieron al lado de los perseguidores, auxiliándolos o encubriéndolos, los judíos Roberto Haberman, Ernest Groening, Frank

53 BORREGO, Salvador, Derrota Mundial. Supracapitalismo y marxismo en pareja globalizadora, México, s/ed., 2012, p. 27.

54 ROMANESCU, Traian, La Gran Conspiración Judía, México, s/ed., 1971, p. 457. 
Tannenbaum, Walter Lippman, Goldschmidt, Oachs, Mauricio de Hirsch y algunos otros." 55

Si bien, este último material repite el modelo de los anteriores, ofrece algunos elementos novedosos. Pero lo más llamativo del texto tiene que ver con el autor que es presentado al principio como alguien perseguido por el judaísmo internacional luego de haber denunciado la conspiración y que, en consecuencia, se ha refugiado en Occidente. De acuerdo con el antiguo miembro de la dirigencia yunquista entrevistado, Romanescu había sido un profesor venido a menos que sobrevivió escribiendo sobre la supuesta conspiración desde los Estados Unidos, ${ }^{56}$ aunque versiones dispersas apuntarían a la inexistencia del personaje y a que el material impreso fue manufactura de los Tecos.

Si la primera versión es cierta, abonaría a la idea de redes anticomunistas con un trasfondo conspirativo a lo largo del continente, mientras que si aceptamos la segunda versión podríamos pensar en una producción propia más sofisticada de dispositivos ideológicos por parte de los grupos secretoreservados hacia mediados del siglo XX.

En cualquier caso, los cuatro textos referidos comparten un trasfondo que los vuelve compatibles entre sí, especialmente en la medida que la contundencia de sus afirmaciones sumada al repetido criterio de autoridad, opacaban las contradicciones y ambigüedades de los argumentos cuya veracidad resultaba irrefutable para los lectores imbuidos en un código constantemente reforzado tanto por los miembros de la institución eclesiástica como por los mismos compañeros de la experiencia secreta. Así, más allá de los datos, el código era susceptible de ser aplicado a los casos mexicano y soviético sin mayores complicaciones gracias a lugares comunes: los golpes de Estado simultáneos, la falsa pugna entre capitalismo y comunismo, así como la supuesta presencia de judíos detrás de cada caudillo.

55 ROMANESCU, Traian, Ob. cit., p. 469.

${ }^{56}$ Entrevista a Manuel Antonio Díaz Cid, realizada por Mario Virgilio Santiago Jiménez, Puebla, México, 20 de febrero de 2012. 
De esta forma, para los católicos militantes de grupos secreto-reservados, la idea de una revolución mexicana bolchevique o una revolución rusa replicada en suelo mexicano ya no dependía exclusivamente del "juego de espejos" promovido por los regímenes, la visión de extranjeros ni de las "pruebas" aportadas por los pocos comunistas mexicanos, sino que paradójicamente era evidente por ser producto de una conspiración secreta milenaria y sólo podría ser derrotada desde las sombras de otra conspiración.

\section{Consideraciones finales}

La respuesta organizada o semi-organizada de numerosos católicos ante la "persecución revolucionaria" fue producto de la experiencia decimonónica de confrontación con el Estado liberal y del pensamiento integral intransigente importado y adaptado. Esto, aunado a las "pruebas" aportadas por los regímenes, redujo el número de lecturas posibles sobre el proceso revolucionario mexicano.

Una de las formas de militancia que surgió como necesidad y que luego derivó en una vía válida por sí misma fue la secreto-reservada. Esta dinámica, sin embargo, replicó el "juego de espejos" dentro del universo católico al confrontar a seglares, clérigos y obispos en torno a la viabilidad de dicha forma de participación política. La existencia de las agrupaciones secreto-reservadas dependía en buena medida de su capacidad organizativa, la fidelidad y cohesión de sus integrantes, así como del respaldo que podían ofrecer miembros de la Iglesia. Visto desde otro ángulo, esta protección también permitió que se consolidara un código ideológico cada vez más sólido fundado en principios conspirativos. Ahí cobraron especial relevancia los asesores, quienes fungieron como vehículos y guardianes de las ideas, así como los textos que las reforzaron y moldearon.

Puesto así, la militancia secreta con un código conspirativo que veía en la revolución mexicana un claro componente bolchevique, podría parecer una colección de ideas y prácticas sin fundamento, pero desde el ángulo de los iniciados se erigía como una forma de descubrir la verdadera naturaleza de las fuerzas que dirigen al mundo: una conspiración milenaria contra la civilización 
cristiana que ha promovido ideologías y revoluciones, como la rusa y la mexicana, para lograr su cometido.

En ese sentido, para tecos y yunquistas la referencia de la revolución rusa fue fundamental en su constitución ideológica e identitaria, con la importante diferencia de que para los primeros la asociación entre revoluciones fue un proceso contemporáneo a su origen, mientras que para los segundos resultó una memoria heredada. Además, dichas memorias estuvieron sujetas a reelaboraciones y adaptaciones durante los siguientes años, especialmente si consideramos que los grupos se separaron en 1965 luego del Concilio Vaticano II, pues los tecos se declararon sedevacantistas al considerar que el Papa era un judío infiltrado, y luego comenzaron una pelea por la presencia en universidades del país que incluyó asesinatos.

Sería difícil sostener que el código se ha mantenido incólume ante el impacto de la revolución cubana, el fin de la guerra fría o el desgaste del régimen de partido hegemónico en México. Sin embargo, lo que muestran las citas del primer apartado de este texto, es que fue efectiva la cobertura eclesiástica así como los mecanismos de transmisión al interior de grupos cuya lectura histórica, aunque con matices, sigue sosteniendo que la revolución mexicana se sovietizó o que la revolución rusa encontró asiento en México.

$-\mathrm{OoOoo}$

\section{Bibliografía}

AGUIRRE Cristiani, María Gabriela, "Entre revolucionarios y católicos: un proyecto de nación, 1913-1917", Yves SOLÍS; Franco SAVARINO (coords.), El anticlericalismo en Europa y América Latina. Una visión transatlántica, México, INAH / CONACULTA / Universidad Católica Portuguesa-Centro de Estudios de Historia Religiosa, 2011, pp. 155-171.

ALEJOS Grau, Carmen José, "La evangelización en los concilios celebrados en América Latina entre 1899 y 1957", Annuarium Historiae Conciliorum, no. 44, 2012, pp. 241-262.

ASPE Armella, María Luisa, La formación social y política de los católicos mexicanos. La Acción Católica Mexicana y la Unión Nacional de Estudiantes Católicos, 1929-1958, México, Universidad Iberoamericana / Instituto Mexicano de Doctrina Social Cristiana, 2008. 
BLANCARTE, Roberto, "La Doctrina Social del Episcopado católico mexicano", Roberto BLANCARTE (comp.), El pensamiento social de los católicos mexicanos, México, Fondo de Cultura Económica, 1996, pp. 19-38.

BORREGO, Salvador, Derrota Mundial. Supracapitalismo y marxismo en pareja globalizadora, México, s/ed., 2012.

CAIMARI, Lila, Perón y la Iglesia católica. Religión, Estado y sociedad en la Argentina (1943-1955), Buenos Aires, Emecé, 2010.

CARR, Barry, La izquierda mexicana a través del siglo XX, México, Ediciones Era, 1996.

COHN, Norman, El mito de la conspiración judía mundial. Los Protocolos de los Sabios de Sión, Madrid, Alianza Editorial, 2010.

DELGADO, Álvaro, El Yunque. La ultraderecha en el poder, México, Ed. Grijalbo, 2003.

DE ROUX, Rodolfo R., "La romanización de la Iglesia católica en América Latina: una estrategia de larga duración”, Pro-Posições, Faculdade de Educação- Universidade Estadual de Campinas, vol. 25, no.1, eneroabril, 2014.

DI STEFANO, Roberto; ZANATTA, Loris, Historia de la Iglesia argentina. Desde la Conquista hasta fines del siglo XX, Buenos Aires, GrijalboMondadori, 2000.

GARCÍA Ugarte, Marta Eugenia, "La mentalidad católica y la política liberal”, Riccardo Cannelli, Nación católica y estado laico. El conflicto políticoreligioso en México desde la Independencia hasta la Revolución (18211914), México, Instituto Nacional de Estudios Históricos de las Revoluciones de México / SEP, 2012.

GONZÁLEZ, Fernando M., "Los orígenes y el comienzo de una universidad católica: sociedades secretas y jesuitas”, Historia y Grafía, Universidad Iberoamericana, No. 20, 2003, pp. 151-205.

GONZÁLEZ, Fernando M., Matar y morir por Cristo Rey. Aspectos de la cristiada, México, Instituto de Investigaciones Sociales - UNAM / Plaza y Valdés Editores, 2001.

GUTIÉRREZ Casillas, José, Jesuitas en México durante el siglo XX, México, Ed. Porrúa, 1981.

LEDIT, Joseph, El frente de los pobres, México, Ediciones Spes, 1955.

Los Protocolos de los Sabios de Sión. Los peligros judío-masónicos, México, Berbera Editores, 2005.

LOUVIER Calderón, Juan; DÍAZ Cid, Manuel; ARRUBARRENA Aragón, José Antonio, Autonomía universitaria. Luchas de 1956 a 1991. Génesis de la UPAEP, México, Instituto de Investigaciones Humanísticas Universidad Popular Autónoma del Estado de Puebla, 1991.

LVOVICH, Daniel, Nacionalismo y Antisemitismo en la Argentina, Buenos Aires, Ediciones B, 2003.

MARTÍNEZ Assad, Carlos, El laboratorio de la revolución. El Tabasco garridista, Siglo XXI Editores, México, 1979. 
MEINVIELLE, Julio, El judío. La teología en defensa del catolicismo, México, Ediciones R.T.S.A., 1959.

MENDOZA Cornejo, Alfredo, Organizaciones y movimientos estudiantiles en Jalisco de 1900 a 1937, México, Universidad de Guadalajara, 1989.

MEYER, Jean, Cincuenta años de radicalismo: la Iglesia católica, la derecha y la izquierda en América Latina, México, Instituto Mexicano de Doctrina Social Cristiana, 1990.

MEYER, Jean, “Disidencia jesuita”, Nexos [en línea], México, 1 de diciembre, 1981, <http://www.nexos.com.mx/?p=3966>.

MEYER, Jean, La cristiada. Los cristeros, México, Siglo XXI Editores, 1974.

O’DOGHERTY Madrazo, Laura, De urnas y sotanas. El Partido Católico Nacional en Jalisco, México, Consejo Nacional para la Cultura y las Artes / UNAM, 2001.

ORTOLL, Servando, "Las Legiones, La Base y el Sinarquismo. ¿Tres organizaciones distintas y un solo fin verdadero? (1929-1948)”, Rodolfo MORÁN, (comp.), La política y el cielo. Movimientos religiosos en el México contemporáneo, México, Universidad de Guadalajara, 1990, pp. 73-117.

PALOMERA, Esteban J., La obra educativa de los jesuitas en Puebla, 15781945, México, Universidad Iberoamericana / Instituto Oriente / Benemérita Universidad Autónoma de Puebla, 1999.

PÉREZ Montfort, Ricardo, Hispanismo y Falange: los sueños imperiales de la derecha española y México, México, Fondo de Cultura Económica, 1992.

POULAT, Émile, Intégrisme et catholicisme intégral. Un réseau secret international antimoderniste: la "Sapinière" (1909-1921), París, Casterman, 1969.

RIUS Facius, iExcomulgado! Trayectoria y pensamiento del Pbro. Dr. Joaquín Sáenz Arriaga, México, Costa-Amic Editores, 1980.

RIVERA Ortiz, Mario Héctor, El estudiantado, una nueva clase social. Acontecimientos cardinales en la historia del estudiantado de la Universidad de Guadalajara en el periodo 1933-1991, México, Edición del autor, 2007.

RODRÍGUEZ López, Rafael, "Semblanza histórica de la Universidad Autónoma de Guadalajara”, ponencia presentada en el Congreso Nacional sobre Historia de la Educación Superior en México, México, Tijuana, Baja California, 8 de noviembre de 2000.

ROMANESCU, Traian, La Gran Conspiración Judía, México, s/ed., 1971

SANTIAGO Jiménez, Mario Virgilio, "Entre el secreto y las calles. Nacionalistas y católicos contra la 'conspiración de la modernidad': El Yunque de México y Tacuara de Argentina (1953-1964)”, tesis de doctorado en Historia Moderna y Contemporánea, México, Instituto de Investigaciones Dr. José María Luis Mora, 2016.

SANTIAGO Jiménez, Mario Virgilio, "Julio Meinvielle, tacuaras, los Tecos y El Yunque contra la "infiltración roja” en México y Argentina”, Cahier des 
Amériques latines, París, Institut des hautes études de l'Amérique latineuniversité Sorbonne Nouvelle-Paris 3, no. 79, 2015/2, pp. 55-74.

SERRANO Álvarez, Pablo, "La 'batalla del espíritu': el movimiento sinarquista en el Bajío Mexicano (1934-1951)”, Rodolfo MORÁN, (comp.), La política y el cielo. Movimientos religiosos en el México contemporáneo, México, Universidad de Guadalajara, 1990, pp. 119-161.

SOLÍS, Yves, "Asociación espiritual o masonería católica: la U”, Istor. Revista de historia internacional, Centro de Investigación y Docencia Económicas, No. 33, verano, 2008, año 9, pp. 121-137.

SOLÍS, Yves, "El origen de la ultraderecha en México: la "U”", El Cotidiano. Revista de la realidad mexicana actual, Universidad Autónoma Metropolitana - Azcapotzalco, no. 149, mayo-junio, 2008, vol. 23, pp. 25-57.

URÍAS Horcasitas, Beatriz, "Retórica, ficción y espejismo: tres imágenes de un México bolchevique (1920-1940)", Relaciones. Estudios de historia y sociedad, El Colegio de Michoacán, vol. 26, no. 101, 2005, pp. 261-300

VACA, Agustín, Los silencios de la historia: las cristeras, México, El Colegio de Jalisco, 1998.

YANKELEVICH, Pablo, La educación socialista, México, Departamento de Educación Pública del Estado de Jalisco, 1985. 